\title{
EL ENSAYO, ENTRE AUTOBIOGRAFÍA INTELECTUAL, BIOGRAFÍA NACIONAL Y CIENCIA SOCIAL: GILBERTO FREYRE, EZEQUIEL MARTÍNEZ ESTRADA Y SÉRGIO BUARQUE DE HOLANDA
}

\author{
Marcela Croce
}

RESUMEN: El artículo se concentra en tres ensayos sobre el "ser nacional" que surgen en el Cono Sur en la década de 1930 en Argentina y Brasil, Casa-grande $\mathcal{E}$ senzala, Radiografía de la pampa y Raizes do Brasil. Los que escriben Gilberto Freyre y Ezequiel Martínez Estrada en 1933 tienen la impronta esencialista que se expande en enunciados apodícticos, más mesurados e intimistas en el caso del brasileño, más incisivos y desalentados en la práctica del argentino. La comparación entre estos dos textos mayores de las respectivas literaturas revela una serie de coincidencias y de contrastes cuya adscripción a principios deterministas, pese a recurrir a múltiples citas de la antropología y de la sociología, renuncia a articular un discurso argumentativamente convincente. Mientras Freyre avanza por intuiciones emocionales, Martínez Estrada despliega el texto con una capacidad retórica superlativa que solamente logra convencer por la precisión estilística, suspendiendo el razonamiento coherente y justificado. Frente a tales modelos excesivos, Sérgio Buarque de Holanda introduce en 1936 una posibilidad de síntesis, apelando a indagaciones históricas y filosóficas, trazando un parangón entre las conquistas hispana y portuguesa en América y aplicando conceptos novedosos con voluntad de desarrollar las ciencias sociales en el continente. A las expansiones nostálgicas de Freyre y a las amarguras escépticas de Martínez Estrada, Buarque les responde con cierta fe optimista en el "hombre cordial" como arquetipo brasileño, incurriendo en la recaída esencialista pero matizándola, lo que abre el camino al desarrollo de la sociología en el ensayo latinoamericano.

Palabras clave: Ensayo esencialista - Gilberto Freyre - Martínez Estrada Sérgio Buarque

\footnotetext{
${ }^{8}$ Doctora en Letras. Profesora en la Facultad de Filosofia y Letras/Departamento de Letras Universidad de Buenos Aires - UBA, Buenos Aires, Argentina
} 
RESUMO: $\mathrm{O}$ artigo se concentra em três ensaios sobre o "ser nacional" que surgem no Cone Sul, na década de 1930, na Argentina e no Brasil: Casa-grande $\mathcal{E}$ senzala, Radiografia de la pampa e Raizes do Brasil. Os que escrevem Gilberto Freyre e Ezequiel Martínez Estrada, em 1933, têm o tom essencialista que se expande em enunciados apodíticos, mais mesurados e intimistas no caso do brasileiro, mais incisivos e desanimados na escrita do argentino. A comparação entre estes dois textos maiores das respectivas literaturas revela uma série de coincidências e de contrastes cuja adesão a princípios deterministas, apesar de recorrer a múltiplas citações tomadas à antropologia e à sociologia, renuncia a articular um discurso argumentativamente convincente. Enquanto Freyre avança por meio de intuições emocionais, Martínez Estrada desdobra o texto com uma capacidade retórica superlativa que somente consegue convencer pela precisão estilistica, suspendendo o raciocínio coerente e justificado. Frente a tais modelos excessivos, Sérgio Buarque de Holanda introduz em 1936 uma possibilidade de síntese, apelando a indagações históricas e filosóficas, traçando um paralelo entre as conquistas espanhola e portuguesa nas Américas e aplicando conceitos inovadores com vontade de desenvolver as ciências sociais no continente. Às expansões nostálgicas de Freyre e as amarguras céticas de Martínez Estrada, Buarque de Holanda responde com certa fé otimista no "homem cordial" como arquétipo brasileiro, incorrendo na recaída essencialista, porém matizando-a, o que abre o caminho para desenvolvimento da sociologia no ensaio latino-americano. Palavras-chave: Ensaio essencialista - Gilberto Freyre - Martínez Estrada Sérgio Buarque

\section{Ejercicios espirituales}

Un recorrido por la crítica brasileña permite comprobar que el modo habitual de abordar un ensayo excesivo como Casa-grande $\mathbb{E}$ senzala (1933) de Gilberto Freyre es impregnándose de la misma grandilocuencia que trasunta el libro. Baste destacar dos miradas privilegiadas en tal consideración que tributan por igual a la fascinación y al rechazo: la de Astrojildo Pereira, contemporánea al texto, y la de Darcy Ribeiro, convocada con la finalidad de integrar, mediante un prólogo, ese monumento brasileño al canon latinoamericano al insertarlo en la Biblioteca Ayacucho fundada en 1974. Para Pereira, la obra de Freyre representaba tres novedades en el campo intelectual brasileño: se trataba 
de un texto literario indisimulable detrás de los afanes antropológicos, implicaba un cambio de vocabulario que otorgaba el estatuto del uso admitido a cierto léxico que estaba tácitamente condenado por su vulgaridad y "tenía como protagonista central no a los héroes oficiales sino a la masa anónima" (apud RIBEIRO, 1977, p. X) rompiendo con la práctica habitual de la República Velha (VIEIRA BORBA, 2011, p. 195). En la perspectiva de que disponía Ribeiro al cabo de las cuatro décadas transcurridas desde la primera edición, y habida cuenta de la circulación que podía recomponerse a través de reediciones y reimpresiones, parecía natural estampar a poco de iniciado el prólogo un parangón desmedido: "En cierta medida Gilberto Freyre fundó Brasil en el plano cultural tal como Cervantes lo hizo con España, Camoens con Portugal, Tolstoi con Rusia, Sartre con Francia (RIBEIRO, 1977, p. X).

Semejante catálogo, además de arrastrar una heterogeneidad riesgosa, resulta asistido por la insolvencia. Pero asimismo registra una virtud que habilita un enfoque sin duda más productivo que los esforzados juicios de valor que se han barajado a fin de conceder condición mayúscula a Casa-grande $\mathcal{E}$ senzala: sugiere un estudio comparativo del empeño de Freyre por indagar la formación de Brasil. El conocimiento pormenorizado del país obliga a trazar un primer lazo con la otra figura que domina el canon del siglo XX, la de Euclides da Cunha. Si, según el propio Freyre, "Euclides escribe como un amerindio, un caboclo", Ribeiro completa la frase pontificando que "Gilberto escribió como un neo-lusitano, como un dominador” (RIBEIRO, 1977, p. XI). Es sintomático que en este reparto de identidades, pese a la reivindicación negrista que consta en multitud de páginas de la obra y que constituye el tópico más transitado de Casa-grande $\mathcal{E}$ senzala, el negro persista siendo figura carente de voz en Brasil, opacado por las certezas autolegitimantes del descendiente de conquistadores.

Las otras comparaciones en las que abunda Ribeiro se entregan a glosar las observaciones de Freyre y operan por supresión. El portugués es aquello que los otros no son; se trata de "un español sin el ardor guerrero ni la ortodoxia; un inglés sin las duras líneas puritanas" (RIBEIRO, 1977, p. XIII). El sujeto luso es positivo por defecto: desprovisto de cualquier rasgo particularizador, soporta la ventaja de suspender aquellas características que en otros pueblos se han vuelto en su contra. La ortodoxia desenfrenada de los españoles encontró su manifestación más grosera en la Inquisición cuyo ojo omnivigilante penetró todos los recovecos de la vida íntima. Esa proximidad que el luso tuvo con su vecino de la península ibérica redundó 
en una vida colonial controlada en Brasil, que eludió las confesiones laicas para remitirlas exclusivamente al ámbito eclesial y suprimió de ese modo la literatura autobiográfica. Acaso como resarcimiento por los siglos de silencio y represión, el Brasil del siglo XX no vaciló ante la autobiografía, y es sugestivo situar el mismo ensayo de Freyre en ese rubro.

Una autobiografía pautada como ejercicio jesuítico: es el mismo Gilberto quien, en el prefacio a la segunda edición de Casa-grande $\mathcal{E}$ senzala, postula los Ejercicios espirituales de Ignacio de Loyola como método de conocimiento, en tanto práctica de introspección (FREYRE, 1966, p. LXV). Tal preferencia por lo recoleto y la intimidad es la que permite elevar la relación de los señores de la casa grande con los esclavos de la senzala a matriz fundacional de la sociedad brasileña. Como advierte Ribeiro, no hay en esas especulaciones método sociológico sino puro impresionismo, resistente a la exigencia de "un desarrollo teórico, abstracto, sobre la naturaleza de las relaciones sociales" (RIBEIRO, 1977, p. XIX). Y si semejante plan le permitió a Freyre esquivar las generalizaciones deterministas en que se habían expandido algunas figuras de las décadas previas como Raimundo Nina Rodrigues y Francisco José de Oliveira Viana, no por eso su procedimiento abandonaba la arbitrariedad, sino que se lanzaba a ejercer la irrefrenable tendencia a privilegiar tesis prejuiciosas y descartar hipótesis demostrables, negando la voluntad inicial de postular un trabajo científico y optando definitivamente por el ensayo literario.

Sin embargo, ante la pobreza de un panorama intelectual como el que habían combatido Manuel Bomfin y Roquette Pinto, la originalidad del trabajo de Freyre lo consagra como bandeirante en tanto "abridor de nuevos caminos" (RIBEIRO, 1977, p. XXIV), y en tal sentido se sobrepone a la repetición condenatoria que desde el Río de la Plata lanza a modo de anatema Ezequiel Martínez Estrada en Radiografia de la pampa en ese mismo año 1933. Lo que en Freyre es la "causa circular" por la cual todo es causa de todo y en consecuencia no existen causas eficientes, en Martínez Estrada adquiere la enunciación profética -finalmente, el nombre Ezequiel actúa como garantía de semejantes énfasis discursivos- arraigada en un determinismo tectónico que suma a la condición misma de la tierra la infecundidad de un relieve llano que conspira contra todo ejercicio de imaginación. Freyre se une a Martínez Estrada en cierta nota pesimista, aunque en el argentino es determinista y en el brasileño modificable. Brasil es una suma de negatividades: mala alimentación, adaptación deficiente al clima tórrido, pobreza química del suelo (FREYRE, 1966, p. 46); sin 
embargo, el elemento humano permite construir una cultura allí donde todo conspiraba contra ella.

Ese elemento humano excluye al indio, en lo que acaso constituye la coincidencia mayor entre Freyre y Martínez Estrada. En la prosa ofuscada de Radiografía de la pampa, la estribación final de América cobijó a las tribus menos significativas en términos económicos y culturales. Frente al esplendor de aztecas e incas que se organizaron como imperios, el territorio más austral del continente se limitó a la precariedad adjudicada a diaguitas, comechingones, araucanos y pampas. A un relieve sin sorpresas, expuesto a una visibilidad absoluta y sometido por igual a los vientos marítimos y los cordilleranos que no permiten que quede en pie ninguna creación, se añaden estos habitantes dotados casi en exclusiva de incapacidades en el pesimismo irredento del libro. Para Gilberto, el indio es aquello que desea erradicar de la nación brasileña en abierta contraposición con el negro. La condición dionisíaca del negro, con su carácter activo en el sentido nietzscheano de quien inaugura un emprendimiento, entra en contraste con el carácter apolíneo del indio, que tiende a plegarse a lo reactivo, rechazando cualquier actividad. Es por eso que según la febril lectura de Freyre el indio no ha dejado una impronta destacada en la cultura brasileña, en tanto el negro despliega un conjunto de aportes que abarcan los bailes, la música, los relatos que las amas de cría les cuentan a los niños de la casa grande, las comidas y especialmente los dulces con que estimulan su gusto, confluyendo en un folklore de todas las regiones africanas involucradas en el tráfico de esclavos desarrollado por los portugueses en el marco de su plan de conquista.

Lo que en esta mirada descarnada hacia el habitante natural del territorio brasileño modula Freyre es que el negro no es un elemento autóctono de América sino una importación forzosa cumplida por los colonizadores. El negrismo orgulloso que enarbola el autor, en una época en que el Caribe comienza a militar en tal sentido -y produce tanto el fenómeno de la negritud organizado por Aimé Césaire en París con la revista L'étudiant noir (1935) a partir de sus orígenes martiniqueños, como las investigaciones del trinitense Cyril Lionel Robert James condensadas en Los jacobinos negros (1938)--, encuentra un eco favorable en ciertos ámbitos intelectuales, pero se enfrenta radicalmente con el movimiento más significativo del Brasil de la época: el Modernismo surgido en 1922 con la Semana de Arte Moderno y expandido en producciones literarias e 
investigaciones culturales como las que lleva a cabo Mário de Andrade indagando el folklore de las diversas regiones.

Dos rupturas introduce Freyre ante la dominante modernista: por un lado, la de rechazar al indio que había sido enaltecido por el Manifiesto Antropófago (1928) hasta derivar en la fórmula "Tupí or not tupí, that is the question"; por el otro, la de desconocer la relevancia relativa de cada región para optar por elevar la suya propia, el Nordeste, a sintesis nacional. El regionalismo se perfila así como un modernismo reaccionario que, al tiempo que articula la ontogénesis local con la filogénesis familiar (impresa en la dedicatoria a los abuelos pernambucanos), alterna la formación norteamericana de Freyre con Franz Boas en Columbia y la frecuentación de Action Française durante su estadía en París para aplicar la vertiente derechista a su lectura de lo brasileño. Es así como concluye que la situación del esclavo en el Brasil patriarcal es mejor que la del obrero industrial a comienzos del siglo XIX (FREYRE, 1966, p. 23).

En 1926, cuando el Modernismo ya había lanzado el Manifiesto Pau Brasil de 1924, Freyre orientó un pronunciamiento que tituló Manifiesto Regionalista. Pero lo cierto es que el texto se conoció recién en 1952 y, aunque el autor le atribuya la fecha de los años 20, es probable que no haya existido antes y que su aparición a destiempo procurara unificar bajo tal etiqueta aquellos productos que repelían al Modernismo: la novela realista -desde los "ciclos" que crearon José Lins do Rego y Rachel de Queiroz hasta la excepcionalidad de Graciliano Ramos--, el ensayo esencialista y las especulaciones antropológicas que derivaron en la postulación de la Lusotropicología como un recorte cultural amplio en que se reconocían tanto el Brasil como el África de colonización portuguesa y la misma península ibérica. Para este provocador del pensamiento que dispensaba categorías novedosas, España y Portugal formaban parte de África, ese espacio de apropiación del cual, en una de sus múltiples visitas, importó una pareja de angoleños que se convirtieron en sirvientes en su residencia de Santo Antônio do Apipucos.

Es sobre esa complacencia de propietario que en el prefacio a la primera edición de Casa-grande $\mathfrak{E}$ senzala Freyre lamenta "el descalabro de la Abolición" (FREYRE, 1966, p. 64) y defiende el mestizaje como atenuación de la rigidez feudal, aunque debe admitir que el cruce se produce con el sadismo del blanco y el masoquismo de la mujer. Sobre la condición dominadora del señor se asienta la dictadura y se diseña una

\footnotetext{
${ }^{9}$ Todas las traducciones del portugués me pertenecen.
} 
mística política que establece el principio de autoridad en tanto regla de orden. El masoquismo fue un rasgo característico de los cristianos; los paganos resistieron su avance violento mediante la expansión de la cordialidad que será la base del estudio de Sérgio Buarque de Holanda pocos años más tarde.

A la par de las manifestaciones religiosas intolerantes, que apenas si prosperaban en el sector más atrasado de una Europa que predicaba la libertad de cultos menos por expediente de fe que por necesidad comercial, el agrarismo ensoberbecido trasladó desde la península ibérica el régimen de economía territorial que había regido durante la Edad Media; así, el capitalismo que incentivó la conquista fue desplazado en Brasil por la persistencia de un sistema arcaico que no obstante introdujo elementos de explotación propios del nuevo régimen. Pero el equilibrio racial que se desarrolló en las zonas rurales eliminó la lucha de clases típica del capitalismo y se enfrascó en un sucedáneo de solidez social que impactó sobre la "arquitectura pesada, horizontal, de las casas grandes" (FREYRE, 1966, p. XLVI), en cuyos cimientos de fortaleza Gilberto se ufana de reconocer la presencia de la sangre negra.

El énfasis en el feudalismo que asiste a Casa-grande $\mathcal{E}$ senzala se transforma en indagación del capitalismo en el siguiente libro de Freyre, Sobrados e Mucambos, donde insiste nuevamente en la arquitectura como configuración de un orden social. Mientras el ensayo de 1933 se entrega a recomponer la formación de la familia patriarcal brasileña, el de 1936 se ocupa de la decadencia del patriarcado rural y el desarrollo del urbano. Aunque la serie se expande en varios títulos es legítimo situar en Ordem e Progresso (1952) la clausura de la sucesión histórica con la instalación del trabajo libre y el paso de la monarquía a la república, condensado en el lema positivista que refulge en la bandera nacional y sepulta definitivamente las infulas dirigentes de la oligarquía nordestina para ceder el mando republicano a paulistas y mineiros que se alternan en el poder mediante la política popularizada como del "café con leche" por las producciones respectivas de cada estado. Justamente Minas Gerais es señalada como zona heterodoxa por renunciar a la economía de siembra para dedicarse a la cría de ganado.

San Pablo y Pernambuco ocupan los extremos más destacados de una contraposición que evita cualquier resolución dialéctica, y que así como identificaba respectivamente a modernistas y regionalistas se empecina en una colisión entre dimensiones espaciales. San Pablo 
responde a lo horizontal y Pernambuco a lo vertical; la horizontalidad se asocia al nomadismo de quien se traslada por el territorio mientras la verticalidad simboliza el arraigo a la tierra. La movilidad horizontal del bandeirante que avanza en busca de esclavos y de oro (también de indios, a los que captura con la misma saña que recomienda el desdén nordestino hacia su figura) es la contracara de la estabilidad de la casa-grande; de allí al ejercicio verticalista del poder, la traslación es inmediata. La formación de San Pablo es efecto de la acción de moros con oficios; la de Pernambuco, en cambio, reúne a híbridos aristócratas dedicados al cultivo del azúcar (FREYRE, 1966, p. 305). Brasil se certifica así como tierra de desequilibrios en la cual todo ejercicio de conocimiento debe operar los ajustes que reclama la heterodoxia de tal configuración.

Las diferencias subrayan la reivindicación regional que entroniza al Nordeste aristocrático sobre el Sur republicano, dando preferencia al azúcar sobre el café. En este punto, la tesis de Freyre sobre la esclavitud contradice de antemano la que expondrá en 1940 Fernando Ortiz en Contrapunteo cubano del tabaco y el azúcar, para quien el azúcar es un producto externo mientras el tabaco resulta un obsequio americano. En lo que coinciden ambos antropólogos es en reconocer al azúcar como un cultivo que favorece la mano de obra esclava -en tanto el tabaco da paso a los trabajadores libres asalariados, contratados por un período y no atados a la tierra- $y$, sobre todo, en la vocación literaria con que abordan el tratamiento de la cultura y la sociedad nacionales. A la autobiografia clasista que practica Freyre le corresponde en Ortiz una inclinación por la literatura medieval que convoca el "Combate de Don Carnal y Doña Cuaresma" del Libro de Buen Amor del Arcipreste de Hita para mutar esas alegorías en Don Tabaco y Doña Azúcar. Tales figuras ya no aparecen enfrentadas sino consustanciadas, nucleadas en un modelo de transculturación cuya aplicación ha impactado en las teorías locales ilustrando brillantes ejercicios de crítica literaria desde el recorrido de Mariano Picón Salas en De la Conquista a la Independencia (1944) hasta la obra magna de Ángel Rama Transculturación narrativa en América Latina (1982).

En el orden de los vínculos con el ensayo latinoamericano contemporáneo, si Ortiz supera pese a sus veleidades estilísticas el planteo económico-cultural estrecho de Freyre -y la transculturación se ajusta al orden latinoamericano con una amplitud que el lusotropicalismo no habilita--, José Carlos Mariátegui parece invalidarlo en los aspectos políticos y especialmente en la consideración del indio. Para Freyre el indigena es componente execrable de la sociedad brasileña, elemento anómalo que 
ostenta un ocio improductivo (y la preguiça que le atribuye tiene respaldos literarios: el caboclo haragán Jeca Tatú de Monteiro Lobato y la "flojera" que acecha al protagonista de Macunaíma de Mário de Andrade diluyen los íconos del Indianismo romántico que convertía a tamoios y tapuias en héroes nacionales) frente al trabajo infatigable del negro, más adaptable al trópico americano como sostenía con equívoca filantropía el padre Bartolomé de Las Casas. Para Mariátegui, en cambio, el indio reviste una representatividad económica que reemplaza la esclavitud del negro en la sierra peruana y a la vez provee un principio de comunismo idealizado mediante la comunidad incaica del ayllu. Solamente en el prólogo a la tercera edición de Casa-grande $\mathcal{E}$ senzala Freyre admite esa perspectiva, sin descartarla pero relativizándola a condición ocasional y quitándole así su eficacia analítica, además de silenciar a su enunciador: "Fluctuante es también la cuestión, levantada por otro crítico, de la extensión del comunismo -esto es, del comunismo considerado sociológicamente-- entre las sociedades amerindias" (FREYRE, 1966, p. LXXIV).

Si el negro es rescatado frente al indio con una vehemencia militante -llega a identificarlo como "elemento europeizante" (FREYRE, 1966 , p. 429) y mediador catequístico para el indígena-, algo similar ocurre con la reivindicación de los moros ante el desprecio por los judíos. La avaricia hebrea, nunca discutida como estereotipo, se enfrenta a las ventajas culturales de los árabes, quienes serían la razón tanto del cultivo azucarero (trasladado de la Ilha de Madeira a Brasil) como del fantasioso trato humanitario hacia los esclavos que se empeña en demostrar el ensayo, por no abundar en el rol cumplido en la revuelta malê de 1835. Acaso por ese mismo afán de rescatar las raíces islámicas Freyre escoge a Hispanoamérica sobre la despreciada Latinoamérica, con renovado desdén hacia todo lo que conspire contra el tradicionalismo peninsular: "Hispánica y no latina. Católica, teñida de misticismo y de cultura mahometana, y no resultado de la Revolución Francesa o del Renacimiento italiano. En este punto nos colocamos con Antônio Sardinha y contra F. García Calderón" (FREYRE, 1966, p. 335).

Si este aspecto representa una de las disidencias más resonantes con el rechazo de Martínez Estrada hacia España, su convicción de que Portugal no exportó una civilización sino que corrompió las que encontró en su plan de conquista coincide con la condena que el argentino reserva a lo ibérico. También el diagnóstico del resentimiento que sufre el mestizo encuentra una afinidad entre ambos ensayistas, aunque en Brasil se imponga la 
variante de impregnar con su frustración las filas del empleo público en tanto en la Argentina expande su rencor en el manejo proverbial del cuchillo que encuentra en el duelo gauchesco su mejor manifestación. La presencia dominante del elemento negro logra equilibrar en Freyre los juicios obscenamente pesimistas en que se empeña Martínez Estrada: si para el brasileño los criterios de "importación" de africanos operaban como "poderosas fuerzas de selección" (FREYRE, 1966, p. 427), en la perspectiva desolada que asume el argentino cualquier elemento ajeno al territorio tiene la exclusiva función de acentuar el determinismo negativo, como ocurrirá con los inmigrantes.

\section{Un designio tan funesto}

A deliberada distancia de la mirada pretendidamente científica con que Freyre intenta justificar sus convicciones, Martínez Estrada acude exclusivamente al sostén retórico para esparcir sus prejuicios con la precisión de un teorema y la perfección formal de un verso. Un solo registro se ausenta de Radiografía de la pampa: el de la argumentación estricta. Repartiendo sus intereses ensayísticos entre las dos exigencias formuladas por Pascal para la exposición de ideas, la fineza y la geometría, el empecinado diagnosticador de los males argentinos comienza indagando las quimeras que llevaron a los conquistadores a arraigarse en un terreno donde todo prometía provisoriedad. El error soberbio de la ambición colonial amargó a los emprendedores y les garantizó una descendencia de conquistados y segundones que apenas si fueron capaces de producir una cultura viciada en la cual ningún transplante fructificaría. Las fallas del sistema, o la ausencia de él, produjeron una serie de espejismos a los que Martínez Estrada adhiere cuando inscribe su voluntad interpretativa en la serie abierta por el Facundo (1845) de Sarmiento cuando establecía que el problema del país era la extensión, aunque para el radiógrafo esta situación es efecto tanto del desaliento como de la geografía.

A las ciencias sociales en las que abreva Freyre el ensayista de la pampa les opone una espectrografía desalentada. Incrédulo de las fotografías y de cualquier registro visual asentado en la superficie, Martínez Estrada practica una mirada radiográfica que inicia las tentativas de nosografía que dedica a la Argentina: es así como a la Radiografía de la pampa de 1933 le sigue la "microscopía de Buenos Aires" que cumple La cabeza de Goliat en 1940 para ratificar en la capital nacional los males ya identificados en el territorio ampliado. Renuente a las imágenes que alucinaron a los 
conquistadores, condena la tendencia de los ciudadanos porteños a desconfiar de la realidad y creer en la barbaridad; para ello alivia la imaginación y se encierra en esas formas de la percepción que recurren a ortopedias de la vista para ofrecer un paisaje cuyo detallismo amenaza con el horror de los excesos y el extrañamiento de los sentidos habituados a otras dimensiones.

Donde Freyre encontraba un capitalismo errático, demasiado apegado a las formas de dominio feudal como para prosperar en América, Martínez Estrada advierte un "capitalismo bárbaro" (MARTÍNEZ ESTRADA, 1996, p. 10) obstinado en medir lo ilimitado y azaroso de la pampa. Del mismo modo que en la disposición de Buenos Aires, ciudad construida de espaldas al puerto que la alimenta, en América "la historia de la colonización es la marcha de espaldas" (MARTÍNEZ ESTRADA, 1996, p. 11) y en tal aseveración encuentra resonancia el Spengler que distingue entre civilización y cultura para emitir su prognosis fatal en $L a$ decadencia de Occidente (1917). Semejante decadencia queda certificada en esta visión por la circunstancia de que, en vez de adoptar los elementos europeos, la pampa prefirió exportar aquellos productos americanos que podian favorecer dicha cultura sin apropiarse de sus rasgos. Ninguna transculturación es posible para este ensayista irritado que sospecha de los bienes naturales porque arrastra la convicción de que la naturaleza es vengativa y su acción principal en el continente es hostigar al hombre arrebatándole todo aquello con lo que aspira a modificarla.

La autodefinición de Martínez Estrada como "puritano en el burdel" lo lleva a estigmatizar a Sudamérica como vasto prostíbulo en el que las uniones ocasionales derivaron en mestizaje. Freyre quedaba fijado en la violación como origen de una mezcla que encontraba positiva pese al pecado original; el argentino, incómodo con el determinismo pero incapaz de insubordinarse a sus preceptos, asienta en semejante violencia la condición vergonzosa de las instituciones locales, y suma la ineficacia que detecta en las mismas al carácter de trámite apresurado que promovió el coitus interruptus como vínculo normal entre hombres urgidos y mujeres deshonradas. La costumbre del desprecio se naturalizó; lo consuetudinario terminó legitimando las taras de origen y contribuyó a producir un carácter nacional resentido y amargado que encontró en el tango una vía de expresión estética. Acaso para conjurar tan espléndidas desgracias, Sérgio Buarque de Holanda insistiría en 1936 con la figura del hombre cordial como aquel que resiste a las instituciones y promueve vínculos en cuya inmediatez 
naufraga la sociedad organizada pero se conservan ciertos elementos propios de una comunidad afectiva. Si sobre tales bases es imposible establecer una nación moderna, al menos se previene contra la ruptura completa de la solidaridad que campea en la pampa argentina.

Martínez Estrada se comporta, en este enfoque, como una bisagra entre Freyre y Buarque, e insiste en desestabilizar y negativizar aquellos aspectos que los brasileños rescataban como formas de organización social. No hay teorías útiles para los furores explicativos de Radiografía de la pampa ni terapéuticas eficaces para los diagnósticos fatalistas; es por eso que todos los autores convocados, de Freud a Simmel, de Sarmiento a Spengler, acuden a ofrecer su cuota de escepticismo para que el ensayista la vuelva hipertrófica en su análisis. Alli donde Freyre recuperaba aquellas revueltas en las que reconocía un germen de autonomía (la Confederación del Ecuador, la rebelión de los malês), Martínez Estrada desconfía incluso de las guerras de independencia, las que intuye asoladas por la conciencia de un pasado infame. Y las autoridades que en Freyre ocupan las extensas notas al pie tendientes a justificar las hipótesis exacerbadas del texto, y en Buarque ofrecen un modelo de análisis que visita con la complacencia de un iniciado (especialmente las que proceden de la sociología alemana), en Martínez Estrada se estrellan en el encono irredento de quien entiende todo sistema como un engaño, toda ilusión como traición, todo emprendimiento como fracaso.

Si bien es cierto que en ciertos puntos Martínez Estrada retoma a Sarmiento, y en muchos aspectos es posible sostener que Radiografía de la pampa se postula como reescritura del Facundo, (SIGAL, 1996, p. 364), el ensayo de 1933 no vacila en enunciar la paradoja según la cual la civilización no acude a contrarrestar a la barbarie en el territorio pampeano: por eso los militares de carrera fracasaron incluso ante la desbandada de las tropas que respondian a los caudillos del interior y las formas civiles no asistieron gradualmente el reemplazo de las costumbres antiguas sino que fueron impuestas sin justificación, extrapoladas de sociedades heterogéneas a las que campeaban en las provincias y tan violentas en su ejecución como los mismos caciques locales a los que proclamaban domeñar.

Aunque asistido por una voluntad de texto orgánico, Radiografía de la pampa resulta mucho menos sistemático en su exposición que Casa-grande e senzala y Raízes do Brasil. Acaso porque elude la tentación del tratado en la prosa combativa del ensayo, tal vez porque dispensa las citas con el arbitrio de quien busca confirmaciones inmediatas más que con el esfuerzo de quien aspira a adscribirse a un pensamiento. Es por eso que en la copiosa 
magnitud de su planteo existen ciertas zonas que logran independizarse del conjunto, más proclives al artículo puntual que a la postulación desaforada en que se insertan, antes propicias a una fenomenología precisa que a una especulación amplia. Es lo que ocurre con el parágrafo dedicado al cuchillo, que si bien parece desprendido de consideraciones previas en las que se destaca la tendencia del habitante pampeano a la lucha cuerpo a cuerpo en que se asienta el culto del coraje, se erige en órgano del cuerpo más que en instrumento anexo.

El cuchillo corresponde al carácter de un sujeto y reviste la misma eficacia del insulto en tanto promueve un desborde de la agresividad. Es a la vez el símbolo de la tradición y el objeto de su preservación, y reviste la particularidad de ser el único elemento que corrige el vicio de "hurtar el cuerpo" que aqueja a los descendientes de los conquistadores. Como utensilio de barbarie tiene prehistoria y no historia; se ajusta al impulso y resiste la reflexión. El ensayo mismo queda impregnado por las dotes de un arma que se alza como amenaza, desestabiliza al adversario, prevé la dimensión de la herida y se presta a la condición artesanal que le confiere la orfebrería cuando individualiza el arquetipo del cuchillo en la pieza distinguida que es el facón.

En cambio, hay otras zonas del ensayo que trazan una continuidad entre los libros de Martínez Estrada, como la que se ocupa de los ferrocarriles, que prosigue en La cabeza de Goliat. La máquina reviste voluntad unitaria en esta aproximación, y si aquí la alteración del principio geométrico se resuelve en la generalidad según la cual "la línea recta, en estos casos, es la más larga y la más lenta” (MARTÍNEZ ESTRADA, 1996, p. 44), en el ensayo de 1940 se especificará en la comprobación de que la distancia más breve entre dos puntos de la Argentina no es el recorrido recto sino el paso por Buenos Aires, que concentra las terminales ferroviarias. La perversión de las reglas matemáticas es una advertencia respecto de la aplicación de cualquier terapéutica: por eso el ensayista prefiere detenerse en el diagnóstico y dejar el ensayo en el suspenso de la desolación, con el retroceso y la regresión en acecho. Su posición no queda protegida por los expedientes objetivos de las ciencias sociales a los que apelan Freyre y Buarque, sino asolada por las fuerzas reactivas que dominan en Sudamérica hasta mimetizarse con la esterilidad, que hacen del aislamiento y la autocontemplación el único método válido para un territorio resistente a las normas. 
El ensayo de interpretación americana, detrás de sus hipérboles y sus oropeles discursivos, soporta la condena de su condición ruinosa; los capítulos alternan la independencia textual con la continuidad de obras porque, impregnado con la pampa, el conjunto es un cuerpo teratológico, no un organismo previsible. Alli donde el dominio se difumina para hacer proliferar la frontera y donde los próceres tributan antes a la categoría de individuos desesperados que a la de héroes, el tono adecuado es el de la desproporción y la teoría más ajustada es la descabellada. Regida por la paradoja, Radiografía de la pampa se empeña en mostrar el horror de lo propio para concluir que nada es originario de esta geografía pretendidamente virginal: a la par que "todo hombre de llanura es oriundo de otro lugar", el ombú tampoco es un árbol pampeano sino "que sólo concuerda con el paisaje por las raíces” (MARTÍNEZ ESTRADA, 1996, p. 71). La casa típica de la pampa no es la casa-grande de Freyre con sus ínfulas aristocráticas que se erige en modelo sino la que niega la existencia, el contramodelo: la Casa Grande, con sus celosías cerradas, sin ruidos [...] es el pensamiento reprimido de las otras, la casa mala, la casa tabú" (MARTÍNEZ ESTRADA, 1996, p. 73).

$\mathrm{Al}$ ambiente definido por Freyre en la casa señorial y al arquetipo social caracterizado por Buarque en el hombre cordial, Martínez Estrada los desestabiliza con procedimientos simétricos. Si la casa pampeana queda desarticulada de la función que le corresponde en el Nordeste brasileño, la figura del guapo desafía la que traza Buarque sobre los tipos ideales de Max Weber. El guapo no es un sujeto auténtico sino el producto de una atrofia; el ambiente no lo afecta porque tolera la tragedia de la erosión pampeana y en eso reside su ambiguo coraje. La parábola heroica se degrada en su figura como remolino confuso. Reactivo como el indio que Freyre oponía al negro dionisíaco, el guapo no es un individuo triunfante en la lucha por la vida sino alguien que persiste por obstinación prehistórica. Pero sobre todo es una figura de arraigo literario, que encuentra en Juan Moreira y en Don Segundo Sombra sus condensaciones más precisas, equivalentes al Cid Campeador, lo que desplaza a Martín Fierro del lugar de privilegio que le habían asignado Leopoldo Lugones en El payador (1916) y Ricardo Rojas en la Historia de la literatura argentina (1917-1922) y suprime la posibilidad de una épica pampeana.

Quince años más tarde, en 1948, Martínez Estrada acometerá el escrutinio de esa figura en Muerte y transfiguración de Martín Fierro (1948). Semejante indagatoria confirma la devaluación completa del hombre pampeano, jaqueado por el atavismo y la llanura, abandonado por los 
dioses como pontificaba Weber cuando se refería a la secularización de la sociedad moderna. El gaucho abandonado está marcado por la clandestinidad, que es el destino de los intrascendentes; el hecho de que Martín Fierro haya quedado canonizado en el poema es uno de los tantos escándalos sudamericanos, pero en este punto el ensayista debe admitir que el escándalo es productivo y amerita un enfoque más historicista que determinista. Sin embargo, la historia que lo hospeda es tan paradójica como las otras dimensiones interrogadas, de modo que la vaca será elevada a personaje histórico fundamental con la misma irreverencia desazonada con que en Radiografía de la pampa la flora quedaba reducida a puro camuflaje vegetal.

Las fuerzas primitivas que Martínez Estrada divide en tres tipos telúricas, mecánicas y psíquicas- corresponden respectivamente a los aspectos activos y reactivos de Nietzsche, a los que suma los efectos que producen. Entre las primeras se despliegan los personajes ya encarados por Sarmiento como el baqueano y el rastreador, en quienes el determinismo tectónico se inscribe como instinto geográfico que recorta sobre el ojo la sociologia de los sentidos simmeliana. En tales expertos del territorio se precipita el único sujeto de la pampa que en vez de entregarse a la destrucción que domina en sus congéneres aspira a reconstruir un recorrido y a someter una huella a la hermenéutica. Las fuerzas mecánicas son las que atañen a la adaptación de los instrumentos, tanto las herramientas concretas como las legales que desplazan la ley en función del pacto y se asoman a esa forma de vinculación que Buarque comprueba en el caso brasileño como ausencia de normas firmes que transmitió el portugués. Pero si en Brasil es la impronta humana la que impregna la sociabilidad local, en la Argentina son los aspectos geológicos y tectónicos los que inciden en la estructura política, "de modo que sólo hay que levantar la película cívica para que aflore el armazón metálico de la estructura militar. Bajo la pampa, el subsuelo de roca" (MARTÍNEZ ESTRADA, 1996, p. 115).

El radiógrafo de la pampa opera con el estilo que él mismo caracteriza como nietzscheano en Heraldos de la verdad (1956), ese texto sobre el ensayo en el que recorre las obras de Montaigne, Balzac y Nietzsche para elaborar una fenomenología de la forma ensayística a la cual se adscribe. El "filosofar a martillazos" que reivindicaba Nietzsche consiste en el inicio en una afirmación categórica que, aunque situada como punto de partida, es en verdad la conclusión de lo que sigue. De este modo, no se 
procura nunca demostrar el axioma del comienzo ni indicar cómo se llegó a elaborarlo, sino que el mecanismo retórico se ajusta a desarrollar el presupuesto como si fuera indiscutible. El determinismo que sostiene Radiografía de la pampa se apoya en procedimientos homólogos. Toda crítica a semejante disposición queda invalidada, no por falta de argumentos que puedan rebatir los principios martinezestradianos, sino porque cualquier intromisión significa un desbaratamiento de la compleja arquitectura que sostiene el conjunto, un atentado contra la solidez estilistica.

El ensayo avanza no solamente por fortalezas retóricas alli donde flaquea el razonamiento sino también por analogías desbocadas que identifican como procedimientos filosóficos los gestos y las conductas de los personajes típicos, como cuando la compadrada se reconoce como sofisma en tanto resolución de conflictos mediante puñetazos (MARTÍNEZ ESTRADA, 1996, p. 123) o el insulto se define como juicio sintético (idem, 129). En tal sentido, el mismo ensayista se erige en complemento verbal del compadre al formular el sofisma de la argumentación para emitir en realidad un panfleto descorazonado. No son los ejercicios espirituales practicados por Freyre los que sobresalen en Radiografía de la pampa sino los embates contra una orden religiosa entendida como sistema de ingeniería extractiva y método de reclutamiento que se resume en "el plan más atrevido que el despecho de un cínico pudo engendrar en el cráneo de un fanático" (idem, 131). La religión en América no solamente se prestó a someter a los indigenas sino que pervirtió la vida espiritual en ostentación material evidente en basilicas y catedrales.

Semejante predilección exhibicionista atravesó las épocas y se instaló en Buenos Aires donde los rascacielos se adosaron a los terrenos baldíos confirmando la persistencia del desastre. Entre las adhesiones sarmientinas indeclinables que llevan a titular "Argirópolis" el primer capitulo sobre la ciudad, y la preparación del libro de 1940 entregado a indagar la capital, Martínez Estrada se solaza en el recorte urbano, traslada a la ciudad las determinaciones de la pampa y tantea una fenomenología intuitiva en la cual el barrio es un carácter y la calle un pensamiento. El enfrentamiento real que reconoce en Buenos Aires no es el del norte y el sur, que equivale a ricos y pobres, sino el del este y el oeste, el que se mantiene en las inmediaciones del río inmóvil y el que se expande hacia la marginalidad de las zonas alejadas del centro. No es la regionalización de Freyre que opone el Nordeste aristocrático al sur de ascenso burgués, el pasado al futuro, sino el énfasis en el unitarismo que distinguió a la política argentina post rosista. Pero lo que sobresale en ambos ensayos es la 
voluntad de plegarse a la condición nacional: la regionalización brasileña que demoró la formación de un partido político nacional hasta la década del 30 y la pretensión de los intelectuales argentinos de resumir todo el país en la capital.

La sección final de Radiografia de la pampa se ocupa de "Seudoestructuras" que eximen desde su misma nomenclatura errática el análisis de las categorías materialistas. La operatoria desestabilizadora de lo subterráneo le interesa más a este escrutador de profundidades que los enfrentamientos clasistas; las determinaciones tectónicas le resultan más convincentes que las económicas. Sin embargo, no se trata solamente de evadir los sistemas explicativos que escapan a la intuición, sino también de desgarrarse del propio país, ejercitando la mirada del desterrado en suelo nacional que estima la única capaz de desmontar la estructura de simulaciones e hipocresías que hacen del carácter argentino un puro artificio, de todo estilo una desdicha estética y del grotesco criollo el género patrio. Semejante catálogo depresivo hace fulgurar la figura del ensayista como un improvisador en quien la multitud de lecturas no logra decantar en la producción de un sistema.

\section{Una ética emotiva}

Con recursos retóricos más menguados y mayor voluntad constructiva, aunque tal disposición lo lleve a concluir que la condición brasileña -como la americana para Martínez Estrada- es lo provisional, escribe Sérgio Buarque de Holanda en la misma década su ensayo más original, Raizes do Brasil. Antonio Candido se apoya en el texto de 1936 para instalar a Sérgio como voz generacional que produce un "impacto liberador" mediante las resonancias simmelianas con que distingue su contribución a la trilogía del ensayo brasileño, que se completa con el libro inicial de Freyre y Evolução Política do Brasil (1934), donde Caio Prado Júnior introduce la presencia de Marx (Candido, 2008, p. 10). Si Simmel acude en la provisión de ciertas categorías ya transitadas por Martínez Estrada, los tipos ideales de Max Weber aportan el elemento metodológico más ajustado para definir al "hombre cordial" como prototipo local.

La designación había corrido por cuenta de Ribeiro Couto, deslizada con la ausencia de rigor y la vocación sintética con que el brasileño describía, en carta a Alfonso Reyes, al sujeto propio del país. Reyes se asomaba a Brasil en su carácter de embajador y recababa más 
información a través de los vínculos intelectuales que mediante fuentes diplomáticas. Su colega le facilitó una aproximación impresionista a la que Buarque procuró darle un carácter sociológico sometiéndola a la tipología weberiana. Pero tales experimentos encontrarían la cerrada resistencia de los deterministas que, menos liberales que Martínez Estrada, militaban en la derecha política brasileña. Es el caso de Cassiano Ricardo, quien mantuvo en 1948 una polémica con Buarque en la cual sostenía que era la "bondad" y no la cordialidad lo que identificaba al hombre brasileño, descalabrando con semejante reemplazo no solamente la nomenclatura de Raizes do Brasil sino también sus proyecciones.

El hombre cordial reúne en la síntesis de Buarque una serie de rasgos propios del carácter brasileño, aunque en el origen de ese repositorio se encuentra el conquistador portugués y no el habitante local. En el interés por la figura del dominador, aunque sin participar de su prosapia como pretende Freyre, Buarque reduce al indígena a auxiliar del avance luso, como ocurre en el litoral; allí, "donde la expansión de los tupís sufría un hiato, se interrumpía también la colonización blanca" (HOLANDA, 2008, p. 106). El foco del ensayo son, pues, unas raíces que no proceden de la tierra pero que se amarran a ella y la modifican, reaccionando contra los furores tectónicos a los que se plegaba Martínez Estrada. En esta mirada cuya parcialidad apenas si resulta matizada por el expediente de las ciencias sociales, el portugués evidencia una aptitud que le faltó al holandés, cuya plasticidad rudimentaria era compensada "en espíritu de emprendimiento metódico y coordinado, en capacidad de trabajo y cohesión social" (HOLANDA, 2008, p. 62). Como esos rasgos no prosperan en el clima tórrido, la impersonalidad y el ritual que acarreaban los holandeses y que favorecían vínculos estables se estrellaron contra las relaciones sociales pautadas por familiaridad y simpatía que dieron origen tanto a la afectividad que Freyre recompone en la casa-grande como al trato amable que dentro del Estado conseguía más beneficios que cualquier red burocrática.

La cordialidad del portugués arraigado en Brasil deja su impronta en el gusto por los diminutivos (correlativo del modo de pedido contra el modo de orden que Freyre marca como condescendencia del amo hacia aquel cuya función exclusiva es la servidumbre), la preferencia por el nombre frente al apellido, una ética emotiva que no decae ni siquiera ante la sospecha de que los afectos puedan ser fingidos, cierta religiosidad superficial que elude toda ortodoxia y se pronuncia antes por el primitivismo de la veneración que por las fortalezas de la fe, y la inclinación 
por una indisciplina que redunda en falta de cohesión. Pero semejante conjunto no solamente distingue al portugués del holandés que fracasó en su asentamiento nordestino sino, obturando la naturalidad de la explicación, también del español que fue probablemente el más exitoso en la conquista americana.

Es allí cuando el ensayo abunda en dualidades que, si no llegan a una dialectización estricta, superan las limitaciones metodológicas de Freyre y Martínez Estrada en tanto Buarque les concede un carácter creador (BRESSER PEREIRA, 2000, p. 2). En el plan opositivo del libro, la conquista hispánica siguió los cursos de agua en tanto la portuguesa no temió avanzar por tierra, la hispánica fue maritima y la portuguesa fluvial, la primera apuntaba a la dominación política y la otra al interés comercial. Eso no suponía la ausencia de cálculo entre los españoles, sino la aplicación del mismo al trazado regular de las ciudades, a la previsión y a la compensación económica, en tanto los lusos optaron por ciudades ajustadas a la geografía, se lanzaron a la experiencia más que al provecho estricto y se satisficieron con una compensación ficcional que condensa en la épica el ideologema de la colonización. El sistema dual resulta útil para la exposición y puede apaciguar a quien apunta a ordenar conocimientos, pero suele ser apócrifo en su afán paradigmático. Precisamente aquellas condiciones que Buarque atribuye a los españoles son las que Martínez Estrada les niega a quienes conquistaron la pampa, y así como Raizes do Brasil se congratula de la elección hispana de la línea recta y la simetría, el enardecido fustigador argentino desmiente la presencia y la eficacia de semejante geometría y la anexa a los trastornos australes.

En verdad, el "juego de oposiciones y contrastes" (CANDIDO, 2008, p. 20) desplegado por Sérgio no solamente encastra con la sociología alemana de principios del siglo XX sino que, como el ejercicio de Freyre, oscila entre lo sociológico y lo antropológico. El nómada se alza como contracara previsible del sedentario, al modo en que el aventurero luso es la contrapartida del trabajador ("ladrillador") hispano. Así se enfrentan el codicioso de mundo y el supersticioso de medios, aquel que fomenta la difuminación de las fronteras y el que mantiene la visión restringida en la que encuentra seguridades inmediatas. El nexo entre ambos lo provee el negro, que se mestiza con los dos, pese a que la esclavitud a que queda sometido conspira contra la cooperación de actividades. La dificultad de asimilar la figura del negro, acaso por la construcción heroica que le había deparado Freyre, lleva a una de las contradicciones más flagrantes del 
ensayo, que bascula entre atribuir a la laboriosidad del esclavo la molicie ibérica tanto como la inversa, explicar la esclavitud como resultado de la haraganería en tanto dato previo de los peninsulares.

Mientras la esclavitud logra suprimirse con la Ley Áurea de 1888, es imposible en cambio suspender el patriarcalismo que ha impregnado la configuración de la sociedad. La mentalidad invasiva de la casa-grande, que aplica la cordialidad como carácter señorial hasta impregnar lo nacional, trueca la dialéctica de ciudad y aldea por la de ciudad y hacienda. En la creciente diferenciación que Buarque aplica respecto de los modelos europeos por los que se rige quedan anticipadas las "ideas fuera de lugar" que Roberto Schwarz denunciará cuarenta años después: ni la palabra "aldea" ni la designación "campesino" corresponden a realidades concretas americanas. También el fascismo es una noción aberrante en el país, que a lo sumo recae en el "mussolinismo indígena" (HOLANDA, 2008, p. 187) de la Ação Integralista Brasileira (AIB), la cual degradó la energía autocomplaciente del belicismo italiano en "pobres lamentaciones de intelectuales neurasténicos" (Íbid.). Al tiempo que en este punto parece coincidir con la convicción martinezestradiana de la defección de Europa en América, en orden de previsiones dentro de la cultura brasileña Buarque se comporta como un protodesarrollista cuando deplora la incapacidad asociativa de los portugueses que impide la formación de un empresariado nacional.

Contra la vocación profética de Martínez Estrada, ejemplificada en multitud de críticas que adquieren la entonación bíblica del anatema, Sérgio condena la fascinación por las teorías -comenzando por el positivismo cuya prédica determinista eximió del análisis--, en especial cuando se sintetizan en fórmulas y no registran aplicación efectiva. En ellas late la seducción de lo sobrenatural que redunda en evasión literaria, tanto la que promueven los románticos mediante la idealización (de la naturaleza, del indio) como la que instala Machado de Assis conjurando con una ironía de raigambre británica "el horror de nuestra realidad cotidiana" (HOLANDA, 2008, p. 162). Las teorías se vuelven pura literatura; de allí que los ensayos que las impulsan sean literarios más allá de cualquier voluntad de ciencia social. La cordialidad que identifica el ensayo de Sérgio Buarque es el correlato del malandraje: en lugar de abandonar el patriarcalismo y promover relaciones cohesivas lo trasmuta en patrimonialismo y finge establecer una sociedad alli donde apenas si prevalece una comunidad premoderna. 
El aventurero portugués y el pícaro español se reconocen en el malandro brasileño que busca su propio provecho por encima de cualquier beneficio general. Semejante figura literaria tiene la enorme ventaja de atenuar el esquematismo de una sociología apenas aprendida y el carácter idealista que revisten tanto el aventurero como el trabajador en su rol de arquetipos. La superación de las dualidades de Buarque corresponde no a sus desarrollos entusiastas sino a su descendencia. No solamente la de Schwarz y los desarrollistas -liderados por Celso Furtado-, como ya se sugirió, sino también la del mismo Candido que prologa Raizes do Brasil y fue capaz de sistematizar en la "dialéctica del malandraje" los conflictos de un Brasil urbano que reemplazaba la casa-grande por el sobrado, el tipo ideal por el sujeto local y un ensayo antropológico y sociológico por una crítica literaria informada por la sociología pero no subsumida a ella. Las vehemencias interpretativas de Martínez Estrada también encontrarian continuidad en la crítica literaria argentina, no ya la de los obstinados hermeneutas sino la de los polémicos intelectuales cuyo vocero mayor fue David Viñas. Una nueva comparación se abre en este punto para proseguir los paralelismos entre Argentina y Brasil, la de Candido y Viñas. Baste, por ahora, dejar abierta la serie cuya errática morfología fue el propósito de este texto.

\section{REFERENCIAS}

BEIRED, José Luis Bendicho. Sob o Signo da Nova Ordem. Intelectuais autoritários no Brasil e na Argentina (1914-1945). São Paulo: Edições Loyola, 1999.

BRESSER PEREIRA, Luíz Carlos. Relendo Raizes do Brasil. São Paulo: 2000. Disponible en <http://www.bresserpereira.org.br/papers/2000/0071.RelendoRaizesDoBrasil-Holanda.pdf $>$.

CANDIDO, Antonio. Dialéctica del malandraje. In ALMEIDA, Manuel Antônio de. Memorias de un sargento de milicias. Caracas: Biblioteca Ayacucho, 1977.

. El significado de Raizes do Brasil. In HOLANDA, Sérgio Buarque de. Raizes do Brasil. São Paulo: Companhia das Letras, 2008, pp. 9-23. 
CROCE, Marcela. Casa grande, Pampa bárbara, Hombre cordial. In: MC ELROY, Isis Costa y MUSLIP, Eduardo (coord.). Passo da Guanxuma. Contactos culturales entre Argentina y Brasil. Los Polvorines: Universidad Nacional de General Sarmiento, 2013, pp. 53-67.

FERREIRA, Edilaine Custódio. Raizes do Brasil: uma interlocução entre Simmel, Weber e Sérgio Buarque de Holanda. Urutágua nº 5, 2004. Disponible en <http://www.uel.br/revistas/uel/index.php/dominiosdaimagem/article/ view/19356/14746>.

FONSECA, Edson Nery da. Gilberto Freyre de A à Z. Brasília: Ministério da Cultura, Fundação Biblioteca Nacional, Departamento Nacional do LivroZé Mario Editor, 2002.

FREYRE, Gilberto. Casa-grande $\mathcal{E}$ senzala. Formação da Família Brasileira sob o Regime de Economia Patriarcal. Rio de Janeiro: José Olympio Editôra, 1966 (2 vol.).

HOLANDA, Sérgio Buarque de. Raizes do Brasil. São Paulo: Companhia das Letras, 2008.

JAMES, Cyril Lionel Robert. Los jacobinos negros. Buenos Aires: Ediciones Razón y Revolución, 2014.

LEENHARDT, Jacques. Raizes do Brasil de Sérgio Buarque de Holanda. Algumas questões sobre a origem da colonização portuguesa no Brasil. Campinas: Universidade Estadual de Campinas, 2002. Disponible en 〈www.siarq.unicamp.br/sbh/Raizes_do_Brasil_Jacques.pdf>.

MARIÁTEGUI, José Carlos. Siete ensayos de interpretación de la realidad peruana. La Habana: Casa de las América, 1982.

MARTÍNEZ ESTRADA, Ezequiel. La cabeza de Goliat. Buenos Aires: Club del Libro A.L.A., 1940. . Heraldos de la verdad. Buenos Aires: Nova, 1958. 
- Radiografía de la pampa. Edición de Leo Pollmann. Madrid: Colección Archivos, 1996.

ORTIZ, Fernando. Contrapunteo cubano del tabaco y el azúcar. Caracas: Biblioteca Ayacucho, 1978.

PICÓN SALAS, Mariano. De la Conquista a la Independencia. Tres siglos de historia cultural latinoamericana. México: Fondo de Cultura Económica, 1944.

RAMA, Ángel. Transculturación literaria en América Latina. Buenos Aires: El Andariego, 2006.

RIBEIRO, Darcy. Prólogo. In: FREYRE, Gilberto. Casa-grande $\mathcal{E}$ senzala. Caracas: Biblioteca Ayacucho, 1977, pp. IX-XLI.

RIBEIRO, Luíz Carlos. Cordialidade e civilização: a configuração civilizacional brasileira na obra de Sérgio Buarque de Holanda. In: 8vo Simpósio Processo Civilizador, História e Educação, 2004, João Pessoa. Anais do 80 Simpósio Processo Civilizador, História e Educação. João Pessoa: Universidade Federal da Paraíba, 2004. v. 1.

SCHWARZ, Roberto. Ao vencedor as batatas. São Paulo: Duas Cidades, 2007.

SIGAL, León. Itinerario de un autodidacto. In: MARTÍNEZ ESTRADA, Ezequiel. Radiografía de la pampa. Edición de Leo Pollmann. Madrid: Colección Archivos, 1996, pp. 349-384.

SPENGLER, Oswald. La decadencia de Occidente. México: Fondo de Cultura Económica, 1984.

VIEIRA BORBA, Carlos Alberto. A formação do Brasil: uma análise a partir das perspectivas de Caio Prado Júnior e Sérgio Buarque de Holanda. Emblemas. Revista do Departamento de História e Ciências Sociais vol. 8 n 1. Goiana: Universidade Federal de Goiás, 2011, pp. 193-212. 
Recebido em: 05/07/2016

Aceito em: 19/07/2016

Bajo los ojos del sur: viejas fronteras y nuevos espacios en literatura y cultura 